\title{
An Investigation of Transfer of Learning in an English-for-Specific-Academic Writing Course: Teaching for Transfer
}

\author{
Dr. Kalthoum Kassab \\ Lecturer, Department of English, Faculty of Arts and Humanities of Sousse, Sousse University, Tunisia \\ $\triangle$ Corresponding Author: Dr. Kalthoum Kassab, E-mail: kolthoum.kassab@flsh.u-sousse.tn
}

\section{ARTICLE INFORMATION}

Received: January 06, 2021

Accepted: February 23, 2021

Volume: 4

Issue: 2

DOI: 10.32996/ijllt.2021.4.2.21

\section{KEYWORDS}

ESAP, Teaching for learning transfer, near transfer, far transfer, hugging-bridging techniques

\section{ABSTRACT}

Despite its importance, transfer of learning is still an under-explored area of research in EAP contexts. The few EAP studies that investigated this phenomenon were mostly conducted in EGAP contexts. Studies conducted in ESAP contexts and informed by learning transfer theories are still rare. The present study aimed to investigate the impact of a teaching-for-transfer ESAP writing course on students' ability to transfer their new learning to their subject-specific courses in a Tunisian university. The ESAP course design drew on SFL genre theories and teaching-for-transfer principles. Perkins and Salomon's (1988) hugging and bridging strategies were blended into instruction in order to maximize the chances for learning transfer to occur. In addition, elements of Barnett and Ceci's (2002) transfer taxonomy were used to distinguish between near transfer and far transfer. A longitudinal quantitative research design, using repeated measures, was followed. Students' authentic written exams from the ESAP writing course and from three content subjects were analyzed in order to investigate the impact of instruction on learning transfer overtime. Results showed that near transfer occurred quite frequently while far transfer occurred in a constricted manner. The findings suggest that an ESAP writing course that blends teaching-for-transfer principles increases the chances for learning transfer to occur. However, the success of such courses depends on the close collaboration between the writing teachers and the disciplinary lecturers.

\section{Introduction}

There is a general consensus that the purpose of most EAP writing programs is to enable ESL/EFL students write better not only for their writing classes but also for their academic disciplines (Leki \& Carson, 1997). This means that the ultimate goal of any EAP program is to help students transfer their learning from the EAP writing classes to their academic disciplines. Indeed, learning transfer lies at the heart of any EAP program (Johns, 1993). Although this phenomenon has been extensively researched for more than a century in the fields of cognitive and educational psychology, it is still underexplored in EAP contexts. Most of the studies that have been conducted in EAP contexts have explored learning transfer indirectly (e.g., Cheng, 2007; Baik \& Greig, 2009; Counsell, 2011; Terraschke $\&$ Wahid, 2011). A few studies were grounded in learning transfer theories (James, 2008, 2009, 2010a, 2010b, 2012; Zarei \& Rahimi, 2014) and were conducted in English for General Academic (EGAP) contexts. Studies conducted in English for Specific Academic Purposes (ESAP) contexts are still rare (e.g., Shrestha; 2017; Hill, Khoo, \& Hsieh, 2020). In addition, while recently there has been a tendency to direct EAP writing instruction towards teaching for transfer (James, 2014, Green, 2015), studies investigating the impact of this type of instruction on learning transfer to other courses are still, to the best of my knowledge, scarse if not non-existent.

The present study aimed to investigate the impact of a teaching-for-transfer ESAP writing course on students' ability to transfer their new learning to their subject-specific courses. The ESAP course design drew on SFL genre theories and teaching-for-transfer principles. Perkins and Salomon's (1988) hugging and bridging strategies were blended into the ESAP writing course in order to maximize the chances for learning transfer to occur. The study aimed to answer the following research question:

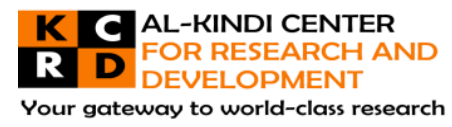

K C AL-KINDI CENTER $R$ D DEVELOPMENT Your gateway to world-class research

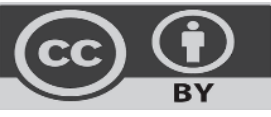

Published by Al-Kindi Center for Research and Development. Copyright (c) the author(s). This open access article is distributed under a Creative Commons Attribution (CC-BY) 4.0 license 
What impact did the teaching-for-transfer ESAP course have on students' writing quality in the ESAP writing course and in other courses at the end of instruction?

It should be noted that transfer of learning in this study was assumed in the improvement that students were expected to demonstrate at the end of instruction. In other words, it did not attempt to identify the learning outcomes that the students were able to transfer from the initial learning context to the targeted transfer contexts. Thus, this study provided only a general picture of transfer of learning.

The next section of the paper reviews the literature that informed the design and implementation of the teaching-for-transfer ESAP writing course. It also reviews the studies that investigated transfer of learning in ESAP contexts. The methodology section describes the research context, the participants, the design of teaching-for-transfer ESAP course, the research design and data analysis. The results and discussion section provides a discussion of the major findings in relation to the existing research findings on transfer of learning in EAP contexts. Finally, the paper concludes with a summary of the major findings, the pedagogical implications of the findings for EAP instructions, and the limitations that should be addressed in future research.

\section{Literature Review}

\subsection{Defining transfer of learning}

Transfer of learning is generally defined as the application of previous learning to new situations. In Perkins' and Salomon's (1992) terms, "transfer of learning occurs when learning in one context or with one set of materials impacts on performance in another context or with other related materials (p. 3)". Research on learning transfer is initially informed by the early work of the educational psychologists Thorndike and Woodworth (1901) who conducted a series of studies to examine the extent to which people transfer. Their work helped cognitive and educational psychologists identify important principles about the conditions that facilitate transfer. One important principle that is believed to facilitate transfer is the degree of mastery of initial learning. Perkins and Salomon (1992) distinguish between ordinary learning and transfer. They refer to ordinary learning as the amount of knowledge that learners can display in a test after a certain period of instruction, while transfer is the learners' ability to use this knowledge in other contexts beyond the test. For example, learner's ability to display some grammar skills in a test is what Perkins and Salomon consider as learning, and learners' ability to apply these grammar skills in real communication is what they consider as "the hopedfor transfer" (p. 3). In other words, transfer "assumes learning within a specific context and asks about impact beyond that context" (Perkins \& Salomon, 1992, p. 3). Obviously, this impact cannot be achieved without a sufficient level of initial learning. Indeed, failure of transfer has often been attributed to inadequate opportunities for students to learn (Bransford \& Schwartz, 1999).

\subsection{Distinguishing between near transfer and far transfer}

Barnett and Ceci (2002) have developed a taxonomy that specifies the dimensions along which transfer can occur and consequently allows for the distinction between near transfer and far transfer. As shown in Table 2.1, this distinction is made in terms of content, referring to what is transferred and context, dealing with transfer distance.

Table 1 Taxonomy for far transfer (Barnett \& Ceci, 2002, p. 621)

\begin{tabular}{llll}
\hline \multicolumn{2}{l}{ A Content: What transferred } & & \\
\hline Learned skill & Procedure & Representation & Principle or heuristic \\
\hline Performance change & Speed & Accuracy & Approach \\
\hline Memory demands & Execute only & Recognize and execute & Recall, recognize and execute \\
\hline
\end{tabular}

\begin{tabular}{|c|c|c|c|c|c|}
\hline \multicolumn{6}{|c|}{ B Context: When and where transferred from and to } \\
\hline \multirow[b]{2}{*}{$\begin{array}{l}\text { Knowledge } \\
\text { domain }\end{array}$} & Near & & & $\rightarrow$ & Far \\
\hline & Mouse vs rat & $\begin{array}{l}\text { Biology vs } \\
\text { botany }\end{array}$ & $\begin{array}{l}\text { Biology vs } \\
\text { economics }\end{array}$ & $\begin{array}{l}\text { Science vs } \\
\text { history }\end{array}$ & Science vs art \\
\hline $\begin{array}{l}\text { Physical } \\
\text { context }\end{array}$ & Same room at school & $\begin{array}{l}\text { Different room at } \\
\text { school }\end{array}$ & $\begin{array}{l}\text { School vs } \\
\text { research lab }\end{array}$ & School vs home & $\begin{array}{l}\text { School vs the } \\
\text { beach }\end{array}$ \\
\hline $\begin{array}{l}\text { Temporal } \\
\text { context }\end{array}$ & Same session & Next day & Weeks later & Months later & Years later \\
\hline
\end{tabular}




\begin{tabular}{llllll}
\hline $\begin{array}{l}\text { Functional } \\
\text { context }\end{array}$ & Both clearly academic & $\begin{array}{l}\text { Both academic } \\
\text { but one non- } \\
\text { evaluative }\end{array}$ & $\begin{array}{l}\text { Academic vs } \\
\text { filling in tax } \\
\text { forms }\end{array}$ & $\begin{array}{l}\text { Academic vs } \\
\text { informal } \\
\text { questionnaire }\end{array}$ & $\begin{array}{l}\text { Academic vs at } \\
\text { play }\end{array}$ \\
\hline $\begin{array}{l}\text { Social } \\
\text { context }\end{array}$ & Both individual & Individual vs pair & $\begin{array}{l}\text { Individual vs } \\
\text { small group }\end{array}$ & $\begin{array}{l}\text { Individual vs } \\
\text { large group }\end{array}$ & $\begin{array}{l}\text { Individual vs } \\
\text { society }\end{array}$ \\
\hline Modality & $\begin{array}{l}\text { Both written, same } \\
\text { format }\end{array}$ & $\begin{array}{l}\text { Both written, } \\
\text { multiple choice } \\
\text { vs essay }\end{array}$ & $\begin{array}{l}\text { Book learning } \\
\text { vs oral exam }\end{array}$ & $\begin{array}{l}\text { Lecture vs wine } \\
\text { tasting }\end{array}$ & $\begin{array}{l}\text { Lecture vs wood } \\
\text { carving }\end{array}$ \\
& & & & & \\
\hline
\end{tabular}

The content factor includes three dimensions pertaining to what transferred. The first dimension relates to the specificity-generality of the learned skill. That is, it indicates whether the learned skill that transfers involves a specific procedure or a more general skill. The second dimension of transfer content, performance change, refers to whether the transfer involves an improvement in the accuracy or the quality of the student's work, the speed of the student's work, and the way the student carries his/her work. Memory demands refers to whether transfer occurs spontaneously or is the result of hints and instructions.

The context of transfer is divided into six dimensions that deal with transfer distance. Barnett and Ceci (2002) view transfer as near or far in terms of knowledge domain, physical context, temporal context, functional context, social context, and modality. Knowledge domain refers to the subject matter to which the skill is to be applied or transferred, for example, an English class versus a history class. Transfer here is considered near or far depending on the similarities that the two subjects share. The physical context refers to whether the training and transfer activities are conducted in the same location and by the same people. For Barnett and Ceci (2002) both types of physical variables can affect the success of transfer. Temporal context relates to the time that separates the training and the testing phases which can be a few minutes later, the next day, weeks later, months later, and even years later. The functional context defines the function that the learned skill serves, for example, whether it is an academic activity involving getting grades or an activity belonging to daily activities outside the academia. The social context refers to whether the learned task is done individually or collaboratively. Finally, modality concerns the format of the task, for example a multiple-choice format versus an essay format. According to Barnett and Ceci (2002), a transfer task may meet the requirements of far transfer on some of these six dimensions but not on others. This means that to be classified as far transfer, a study does not have to satisfy all the criteria for far transfer on all dimensions.

\subsection{Teaching for transfer}

Many instructional frameworks that are believed to promote learning transfer have been proposed (Marini \& Genereux, 1995; Haskell, 2001; Halpern \& Hakel, 2003). However, Perkins and Salomon's (1988) framework for teaching for transfer remains the most influential and the most pervasive model in the transfer literature (Green, 2015). Its usefulness in informing pedagogical practices in the classroom (Butterfield \& Nelson, 1989) has gone beyond general education to reach more recently fields such as ELT (James, 2006) and EAP (Green, 2015). For Perkins and Salomon (1988), the failure to transfer is linked to the prevailing misconception that transfer is an automatic process. That is, all the knowledge and skills that students learn are expected to transfer automatically to other contexts. They mockingly refer to this assumption as "the Bo Peep theory of transfer" (p. 23): the idea that if left alone transfer would take care of itself and would find its own way. For Perkins and Salomon, transfer is a too complex phenomenon to be thought of as an automatic process, and it will be much more difficult to obtain when instruction does not explicitly focus on helping students to transfer. They propose two main instructional techniques that can promote transfer, which they refer to as hugging and bridging. Hugging refers to the teaching that attempts to meet the conditions of low road transfer and thus of near transfer. Bridging is the teaching that attempts to meet the conditions of high road transfer that in turn will promote far transfer. Fogarty, Perkins and Barrel (1992) have translated this bridging-hugging framework into a number of instructional strategies which they have classified into strategies for hugging and strategies for bridging (Table 2). These huggingbridging techniques have been used in general education in the USA, and they have been extended to ELT settings (James, 2006) and more recently to EAP contexts (Green, 2015). The application of these techniques in the present study is also based on Green's (2015) application of Fogarty et al.'s (1992) hugging and bridging techniques in EAP contexts.

Table 2.2 Instructional strategies for teaching for transfer as suggested by Fogarty et al. (1992)

\begin{tabular}{ll}
\hline Hugging & Bridging \\
\hline Setting expectations & Anticipating application \\
\hline Matching & Generalizing concepts \\
\hline Simulating & Using analogies \\
\hline Modelling & Parallel problem solving \\
\hline Problem-based learning & Metacognitive reflection \\
\hline
\end{tabular}


Forgaty et al.'s five instructional techniques for hugging aim to create an initial learning environment which highly resembles the target transfer contexts. Setting expectations means constantly reminding learners how they can use what they learn in the initial learning context in other courses. For students to be able to make this link, the course materials and the assignments should be made as similar as possible to those needed in other courses. This is what is implied by matching. This is an important factor because transfer will be more likely to occur when authentic materials and tasks are used (James, 2006). Simulating means "experiencing the actions and feelings of the actual situation by pretending or approximating the real experience" (Fogarty et al., 1992, p. 45). Thus, simulation activities that can promote transfer in the EAP classroom can be those that are based on materials and questions from other courses (Green, 2015). Modeling is another important instructional strategy that is assumed to promote transfer. It consists of showing students real models of how they can use the skills from the language class in other courses. For example, students can be shown models of how the skills learned in the EAP class are used to produce written texts aimed for other courses (Green, 2015). Finally, problem-based learning could be used by encouraging students to consider ways of how to approach an assignment from other courses (Green, 2015).

The bridging techniques include anticipating applications, generalizing concepts, using analogies, parallel problem-solving, and metacognitive reflection. Anticipating applications implies thinking of future opportunities to use newly learned skills in different contexts. Applied to EAP contexts, students can be encouraged, for example, to think about ways of how they can use certain essay patterns in other courses (Green, 2015). Generalizing concepts means encouraging students to make generalizations about concepts, principles, rules and ideas and determine how they can be applied in different contexts. Training students how to use analogies implies that they learn how to find and analyze analogies, compare, and make connections (Fogarty et al., 1992). Similarly, EAP instruction should encourage students to find similarities and make connections between what is learned in the EAP class and in the other courses (Green, 2015). As for the parallel problem-solving technique, it aims to help students gain "an appreciation for the similarities and contrasts between areas" by involving them in parallel-problem solving activities (Fogarty et al. 1992, p. 85). In EAP contexts, Green (2015) suggests that this could be done by assigning students tasks that are similar to those they are completing at the same time in other courses. The final technique recommended for bridging is metacognitive reflection. It consists of encouraging students to plan, monitor and evaluate their own thinking, which helps them become more aware of their learning progress.

\subsection{Learning transfer in EAP contexts}

To date, very few studies that are grounded in learning transfer theories have been conducted. Shrestha (2017) investigated the role of dynamic assessment in promoting transfer of learning in an ESAP distance learning context in the United Kingdom. Drawing on socio-cultural theories of learning and SFL genre theory, Shrestha (2017) explored the extent to which dynamic assessment, a method that blends assessment into instruction, helped three students transfer genre features and conceptual knowledge from their online academic literacy module to their business studies modules. The ESAP course aimed to familiarize students with a number of genres commonly used in business studies such as case studies, reports, and essays. This is a basic feature of ESAP courses which are expected to promote near transfer. However, Shrestha's (2017) study targeted far transfer because the writing assignments in the business studies course differed in some ways from the writing tasks in the EAP course. The findings showed that dynamic assessment in an ESAP course may promote transfer, though this transfer varied from one participant to another. However, it can be noted that Shrestha's (2017) distinction between near transfer and far transfer was not based on clearly defined dimensions such as those suggested by Barnett and Ceci (2002). In fact, studies that have attempted to examine learning transfer by using Barnett and Ceci's (2002) transfer taxonomy are still rare.

James' (2014) review of transfer research in EAP contexts was the first study that employed Barnett and Ceci's (2002) transfer taxonomy in order to identify the type of transfer that had been reported in 41 studies. One major gap that James (2014) identified in his review is the lack of empirical studies that investigated transfer from EAP instruction to students' work in other courses using the kind of multi-dimensional perspective as suggested by Barnett and Ceci (2002). In a recent study, Hill, Khoo, and Hsieh (2020) employed Barnett and Ceci's taxonomy to investigate the impact of a one-semester engineering ESAP course on learning transfer at a Singapore university. Using a mixed methods approach, analysis of students' writing samples and students' interviews, the researchers sought to know whether the targeted learning outcomes transferred from the engineering ESAP course to students' writing in both the engineering ESAP course and the engineering-specific course assignments. Khoo et al. (2020) found that significant transfer occurred in most of the learning outcomes within the ESAP course, and sustained transfer occurred in half of the learning outcomes from the ESAP course to the students' engineering assignments. While Hill et al. (2020) provided insights into the learning transfer by using some elements of Barnett and Ceci's transfer taxonomy, more research on how this transfer taxonomy can better inform learning transfer in EAP contexts is needed.

Similarly, studies focusing on teaching for transfer in EAP contexts are still rare. There has been some interest in orienting EAP writing instruction towards teaching for transfer by using Perkins and Salomon's (1988) hugging and bridging techniques. For example, James (2006) provided useful guidelines on how these instructional strategies, which are widely used in general education 
in the USA, can be applied in ELT settings. In addition, he frequently pointed to the potential positive impact of these strategies on learning transfer in EAP contexts in his studies on learning transfer (James, 2009, 2010, 2014). Green's (2015) study appears to be the unique study which explored this framework in EAP contexts. In his survey study, Green (2015) revisited the huggingbridging framework to explore the relationship between EAP instructors' teaching techniques and students' perceived transfer of learning to other courses in a university in Thailand. The study involved 39 undergraduate students enrolled in an English communication course. By adapting Fogarty et al.'s (1992) hugging-bridging individual items, Green (2015) did not seek to test their effectiveness in promoting transfer but rather to explore the extent to which the teachers' instructional methods approximated the hugging-bridging techniques. The adapted hugging-bridging individual items were later phrased as Likert-type items for a self-report questionnaire that constituted the main data source of the study.

Green's (2015) study provided interesting information on the role the hugging-bridging techniques can play in promoting transfer in EAP contexts. The findings showed that most of the surveyed students perceived that they had transferred skills related to reading, research, and writing from their EAP course to their disciplinary courses. Green (2015) also found that the combined hugging and bridging techniques were mostly related to the transfer of writing knowledge, which indicates that adapting these techniques to EAP writing instruction can be appropriate. However, he argued that using the hugging-bridging strategies exclusively in the EAP classroom is insufficient in providing a clear picture of the transfer phenomenon. Subject-specific instructors also play an integral role in enhancing the prospects of transfer in many ways. He added that in order to facilitate the application of the learning from the EAP program to their courses, disciplinary instructors should become familiar with the content and targeted outcomes of the EAP programs. This enables them to match their expectations with those of the EAP program and especially to draw their students' attention to opportunities for transfer in their own courses. In sum, Green's (2015) study provided insights into how Fogarty et al.'s (1992) hugging-bridging strategies can be used in EAP contexts to promote transfer. However, learning transfer in this study was explored from students' perspectives only. It remains to see what impact an EAP writing course that focuses on teaching for transfer can have on students' written performance in both the EAP writing course and in other courses.

\section{Methodology}

\subsection{Research context}

As stated previously, the present research aimed to investigate the extent to which an ESAP writing course that was focused on teaching for transfer helped students of English transfer their learning from their writing course to their content courses. The study was conducted at the Faculty of Arts and Humanities of Sousse during the academic year 2015-2016. It involved students of English who were at the final year of their three-year English BA. Students had to study a two-semester academic writing course with other content subjects, including TEFL, literature and cultural studies. The literature courses included drama, poetry, and fiction. The cultural studies course was divided into two main subjects that included British history and American history. These content subjects were selected to be the focus of this study because they all required the written examination prompt as the main form of evaluation at the end of instruction.

\subsection{Course design}

The design of the ESAP writing course drew from SFL genre theory and Content-Based Instruction (CBI). The course was designed around evaluative writing with a focus on the discussion genre and text responses because they seemed quite close to the type of writing the students needed to do in the other subjects. For this, SFL genre theory (Rose \& Martin, 2012) provided a good source of information on the textual and linguistic features of evaluative writing. In addition, the adjunct model of Content-Based Instruction (CBI) was adapted in a way to suit the target context (Richards \& Rodgers, 2014). This teaching model consists of linking an EAP course to a concurrent course and is taught by the EAP teacher and the subject teacher. In this study, the researcher acted as both the EAP teacher and content teacher following the belief that subject specialists should play a direct role in enhancing students' academic literacy development (Wingate, 2016). The EAP writing course was linked to the TEFL course. This consisted of using materials from the TEFL course to teach the targeted skills and writing genres. The ESAP writing course aimed to assist students to:

a. Become familiar with the academic practice specific to the discipline of applied linguistics,

b. Develop the reading and writing skills they need for the targeted subject-specific course (TEFL course),

c. Understand the relationship between reading and writing in academic studies,

d. Master the essay examination genre,

e. Transfer their newly acquired skills to the target transfer context (TEFL course),

f. Develop strategies to transfer the learned skills to other subjects other than the TEFL course (literature and cultural studies). 


\subsection{Teaching for transfer}

As discussed earlier, Perkins and Salomon (1988) argue that transfer of learning can be encouraged on the condition that instruction is focused on teaching for transfer. The hugging-bridging framework they propose for teaching for transfer has been translated into instructional techniques by Fogarty et al. (1992), which in turn have been adapted to EAP contexts by Green (2015). Table 3.3 provides a summary of how the hugging strategies which attempt to meet the conditions of near transfer, were blended into the ESAP writing course.

Right from the beginning, students were told that the writing course would focus on skills and activities that they needed for their writing course as well as their TEFL course. For example, they were constantly reminded that summarizing, paraphrasing, synthesizing, and referencing were essential skills that they needed not only for their writing exams but also for the TEFL exams. They were regularly reminded that the best way to prepare for the TEFL exams was by summarizing and synthesizing their course materials and not by relying on memorizing information. As for the use of in-text-citations, they were regularly warned that a TEFL exam answer would be penalized for plagiarism if it did not cite the source materials appropriately by using the APA style for intext-citations, studied in the writing course. Furthermore, they were regularly reminded that the discussion genre they were practicing in the writing course is a required genre in the TEFL course, and thus they needed to pay attention to its generic and linguistic features when this genre is asked for in the TEFL course.

Table 3.3 Hugging strategies to promote near transfer based on Fogarty et al. (1992) and Green (2015)

\begin{tabular}{ll}
\hline Strategy & Method used by the instructor \\
\hline Stetting expectations & $\begin{array}{l}\text { Students were constantly reminded how and when they can use the skills they } \\
\text { learned in the writing class for the TEFL course. }\end{array}$ \\
\hline Matching & The writing course was linked with the TEFL course. \\
\hline Simulating & $\begin{array}{l}\text { The reading and writing activities were those needed in the TEFL course (e.g., } \\
\text { summarizing, paraphrasing, synthesizing, writing discussion essays). }\end{array}$ \\
\hline Modeling & $\begin{array}{l}\text { Students were provided with examples and models of how they can approach the } \\
\text { assigned TEFL readings and answer TEFL examination prompts. }\end{array}$ \\
\hline Problem-based learning & $\begin{array}{l}\text { Students were asked to do a number of activities without receiving much help from } \\
\text { the teacher (e.g., finding sources for essay writing, preparing an oral presentation } \\
\text { requiring a synthesis of readings). }\end{array}$
\end{tabular}

As for matching, students' learning experiences were made as authentic as possible by focusing the writing course on the content and the activities needed in the TEFL course. Similarly, most practiced activities were the same activities students needed to do for the TEFL course. For example, they practiced writing essays on real TEFL exam topics. They applied the demanding writing skills of summarizing, paraphrasing, and synthesizing to their assigned TEFL readings with the aim to prepare them for their final TEFL examinations at the same time. Concerning modeling, students received real examples of how the skills they were learning can be applied to other courses. For example, they were provided with models on how to answer examination prompts related to TEFL. Modelling also concerned reading strategies such as skimming and scanning. For example, students were shown how they could make effective use of these strategies during the two-hour writing exam. They were also shown when they could resort to these strategies when reading the assigned TEFL readings that were quite long and contained too much information. Finally, concerning problem-based learning, students were often asked to engage in activities that required them to figure out ways of how to approach a task themselves, for example writing a synthesis of readings related to the TEFL course and figuring out ways how to plan and organize the evaluation essay on their own.

Table 3.4 provides a summary of how the bridging techniques were blended into the EAP writing instruction to encourage far transfer. Concerning anticipating applications, students were constantly asked to think about ways how they can use some of the skills learned in the writing class in the other courses, for example, whether the discussion essay was suitable for courses like drama, poetry, and cultural studies. They were also encouraged to see how they can use, for example, their paraphrasing, synthesizing, and referencing skills in cultural studies and literature exams. Generalizing concepts means encouraging students to think about ways how rules and principles can be generalized to other contexts. Students were taught that there are writing rules and principles that must be applied in the literature and cultural studies courses as well. For example, the introduction in an examination essay must contain three moves, introductory statements, thesis, and the scope of the essay; each body paragraph of the essay must start with a topic sentence followed by supporting details, and the conclusion must restate the issue and the main ideas and ends with some kind of final thoughts or recommendations. Another important principle that was emphasized was writing critically. Students were taught that critical thinking is a major characteristic of academic writing; thus, they need to think about ways how they could apply what they have learned about writing critically in the writing class to their literature and cultural studies courses. 
Using analogies is another important principle that is thought to promote far transfer (Gick \& Holyoak, 1983). It involves finding similarities between one situation and another. During the course, students were constantly encouraged to find similarities between what they had learned in the reading/writing course and the literature and cultural studies courses. For example, during the first session of the second semester, students were asked to work in groups and try to identify the similarities and differences between the first semester exam topics in poetry and Anglophone civilization and the kind of essay writing they did in the reading/writing course. During this activity, students' attention was basically drawn to the possible structure, organization, and critical aspect of these essay examination prompts in comparison with the structure, organization, and critical aspect of the essays they practiced writing in the writing course during the first semester. Parallel problem-solving involves asking students to do tasks that are similar to those they have been doing at the same time in other courses. During the writing course, students were encouraged to apply the skills of paraphrasing, summarizing, and synthesizing to the readings they were supposed to do in their literature and cultural studies courses.

Table 3.4 Bridging strategies to promote far transfer based on Fogarty et al. (1992) and Green (2015)

\begin{tabular}{ll}
\hline Strategy & Method used by the instructor \\
\hline Anticipating applications & $\begin{array}{l}\text { Students were encouraged to think of ways in the future in which they may use the } \\
\text { skills from the writing course in literature and cultural studies courses. }\end{array}$ \\
\hline Generalizing concepts & $\begin{array}{l}\text { Students were encouraged to think about how principles and rules they learned in } \\
\text { the writing course could be applied in literature and cultural studies courses. }\end{array}$ \\
\hline Using analogies & $\begin{array}{l}\text { Students were encouraged to find similarities between the writing they did in the } \\
\text { writing class and the writing they needed to do in literature (fiction, drama, poetry) } \\
\text { and cultural studies. }\end{array}$ \\
\hline Parallel problem-solving & $\begin{array}{l}\text { Students were encouraged to summarize and synthesize some reading materials } \\
\text { from their literature and cultural studies courses. }\end{array}$ \\
\hline Metacognitive reflection & $\begin{array}{l}\text { Students were asked to keep a reflective journal in which they had to record their } \\
\text { reflections on their learning on a weekly basis. }\end{array}$ \\
\hline
\end{tabular}

Finally, metacognitive reflection means encouraging students to plan, monitor, and evaluate their own thinking (Anderson, 2002). This implies encouraging students to reflect on the overall cycle of their learning experiences. In order to encourage reflective thinking during writing instruction, students were asked to keep a reflective learning journal in which they recorded their thoughts about their learning experiences in the ESAP writing course. They were asked to write about their reactions, both positive and negative, to the different kinds of activities they were assigned to do in class and outside class. For example, they were encouraged to describe the difficulties they had while writing a discussion essay or reading an article, how they tried to overcome those difficulties, and how they thought they could do better in the future.

\subsection{Distinguishing between near transfer and far transfer}

Since the present study targeted both near and far transfer, a distinction between these two types of transfer was made by following some elements of Barnett and Ceci's (2002) transfer taxonomy. Considering that transfer does not have to reflect all the nine dimensions of the taxonomy (Barnett $\&$ Ceci, 2002; James, 2014), only five dimensions were used. The distinction between near and far transfer was made in relation to the similarities between the initial learning context and the target transfer contexts. This distinction was also informed by James' (2014) application of this transfer taxonomy to EAP contexts.

As shown in Table 3.5, two dimensions related to transfer content were considered. A change in students' performances in all the targeted transfer contexts was expected. But the speed and the quality of the students' work as well as the students' strategies to carry the tasks would differ from one context to another. The writing and the TEFL courses were classified as near because students were expected to do the tasks nearly in the same way given the considerable similarities between the two courses. Literature and cultural studies were classified as far because they differed from the initial learning context in terms of the examination prompts which may be guided by instructions verbs whose purpose may be different from those used in the writing course. Concerning memory demands, the ESAP course and TEFL were classified as near because learning transfer would occur as the result of hints and instructions. Literature and cultural studies were classified as far because transfer would occur rather spontaneously, in that students were expected to find similarities between the initial learning context and the target transfer contexts.

Concerning transfer distance, three dimensions were considered, including the knowledge domain, the physical context, and the temporal context. The knowledge domain deals with transfer distance in terms of topic or subject matter. Near transfer was expected in the ESAP writing course and the TEFL course because the teaching and testing activities were made very similar in terms of content and the type of essay writing. Concerning literature and cultural studies, far transfer was expected because these 
courses differed from the initial learning context in terms of content and activities. In addition, the requirements of the examination prompts in these two subjects may be different from those of the initial learning context.

Table 3.5 Distinction between near and far transfer in terms of the content of transfer (based on Barnett and Ceci (2002) and James (2014)

\begin{tabular}{|l|l|l|l|l|}
\hline Content of transfer & ESAP & TEFL & Literature & Culture studies \\
\hline Performance change & Near & Near & Far & Far \\
\hline Memory demands & Near & Near & Far & Far \\
\hline
\end{tabular}

The physical context refers to whether the teaching and transfer activities are conducted in the same location and by the same people. For the ESAP writing and TEFL courses, transfer was considered as near because testing occurred in a small amphitheater with conditions that did not differ very much from the classroom where learning was conducted. The three third year groups taught by the researcher were gathered in the same amphitheater and were overseen by the researcher and a colleague who kindly volunteered to help. As for literature and cultural studies, transfer was considered as far because learning occurred in a classroom but testing occurred in different locations. The students who were the focus of the study did not take the literature and cultural studies exams together in the same location. They were distributed in different classrooms according to the alphabetical order of their names and were overseen by different teachers. The researcher did not oversee any of them.

Table 3.6 Distinction between near and far transfer in terms of transfer distance (based on Barnett and Ceci (2002) and James (2014)

\begin{tabular}{lllll}
\hline Context (Transfer distance) & ESAP & TEFL & Literature & Cultural studies \\
\hline Knowledge domain & Near & Near & Far & Far \\
\hline Physical context & Near & Near & Far & Far \\
\hline Temporal context & Near & Near & Far & Far \\
\hline
\end{tabular}

Finally, the third dimension that was taken into consideration was the temporal context. It refers to transfer distance in terms of the interval of time between teaching and testing. Concerning the ESAP writing course, near transfer was targeted because it was expected to occur almost immediately at the end of the period of instruction. First, students sat for the writing exam that took place on a Saturday. For group 1, the interval of time between the last writing session and the writing exam was two days and just one day for groups 2 and 3. The TEFL exam was scheduled a week after the writing exam. Because the TEFL course was closely linked to the writing course, students continued receiving instructions on how to write a good TEFL exam answer during the last TEFL session that had preceded the TEFL exam. The interval of time between TEFL instruction and the TEFL exam was two days for groups 2 and 3 and one day for group 1. Finally, concerning literature and cultural studies, far transfer was expected because the interval of time between the end of the initial learning phase and testing was more than three weeks.

\subsection{Participants}

The researcher taught both the ESAP writing course and the TEFL course to three third year groups that included a total number of 89 students in the first semester and 74 students in the second semester. However, the total number of students from whom all the required data could be collected was 40 . They were the students who took the pre-test, attended the writing class regularly during the academic year, and took the final writing exams as well as the final TEFL, literature, and cultural studies exams in both semesters. The students were informed of the purpose of the research at the beginning of the academic year. They were told that the data collection process would not put any extra burden on them nor disturb the natural flow of the lessons. They were requested to allow copies of their written texts that included their ESAP writing exams and the TEFL exams to be used for analysis. As for the literature and cultural studies written exams, permission was sought from the faculty's administration to have access to the students' exams and photocopy them.

\subsection{Research design}

James (2014) asserts that it is important to understand the role that EAP writing instruction can play in learning transfer by determining, for example, "whether the EAP instruction helped students to learn new skills or to improve existing skills, and whether it was the only source of support for this learning" (p. 2). For James, understanding the impact of EAP instruction on learning transfer necessitates the use of experimental research designs that involve an instructional period followed by a posttest that aims to identify what was learned during that instructional period. James also notes that any demonstration of learning necessarily involves transfer. In his review of research on the effect of EAP instruction on learning transfer, James (2014) included studies that used experimental and quasi-experimental research design as well as a variation of an experimental/control group, pretest-posttest design, or times series designs. 
In this study, a longitudinal quantitative design, using repeated measures, was used. A repeated measures design is a common research design in applied linguistics that involves a large number of participants but a few assessment time periods (Dornyei, 2007). One important characteristic of this research design is that it elicits data from each participant in the large sample at two or three points in time. This type of longitudinal quantitative design was considered appropriate for the present research because it allowed the use of authentic assessment time periods. Students' real exams that were taken at different points in time were used in order to determine the effect of EAP writing instruction on students' writing performance as well as its effect on transfer of learning overtime. The research was conducted over a period of two semesters of ESAP writing instruction.

\subsection{Data collection}

The data collection process started in mid-September 2015 and ended in April 2016. Students' written texts were collected at three different points of time to investigate the impact of instruction in the ESAP writing course and on transfer of learning to other courses. In this context, learning transfer was assumed in students' writing performance (James, 2008). Table 3.6 presents a summary of the number of writing samples that were collected from the targeted courses.

Table 3.6 Number of students' writing samples collected for analysis

\begin{tabular}{|c|c|c|c|c|c|c|}
\hline & Pre-test & ESAP & TEFL & Lit. & Cult. stds. & Total \\
\hline Semester 1 & 40 & 40 & 40 & 40 & 40 & $N=360$ \\
\hline Semester 2 & - & 40 & 40 & 40 & 40 & \\
\hline
\end{tabular}

The pre-test was administered at the beginning of the academic year and before EAP writing instruction began. It consisted of a reading-to-write test that was similar to the posttests that students would take in the writing course. Using the same type of essay writing in both the pre-test and the posttests would make the comparisons of essays meaningful (Mackey \& Gass, 2005). In addition, it was considered appropriate to use the same pre-test to compare students' writing performance in the content subjects because it was designed in a way to resemble as much as possible the kind of text-responsible writing (Leki \& Carson, 1997) that is required in subject-specific courses. Moreover, the writing course was an ESAP writing course that aimed to help students transfer their new learning to the other courses.

The pre-test as well as the two end-of-term ESAP writing exams were scored following a slightly modified version of the Jacobs et al.'s (1981) analytic scoring scale. This scale was chosen because it is "one of the best known and most widely used analytic scales in ESL" (Weigle, 2002, p. 115). The use of this scoring rubric was based on what is referred to as the "adopt and adapt" (Crusan, 2010, p. 72) strategy, which means selecting a rubric and modifying it in order to suit the needs of the local context. The adaptation process was informed by other existing rating scales for text-responsible writing such as those described by Weigle (2002). The analytic scale that was also employed to score the TEFL, literature, and cultural studies exams. It was slightly modified in a way that gave more weighting to organization because content subjects generally place most emphasis on content and organization (Weigle, 2002). The TEFL writing samples were first rated by the researcher using the modified scoring rubric along with other task specific criteria. Then, a colleague who taught the TEFL course double-marked the writing samples. As for the literature and cultural studies writing samples, permission was first sought to photocopy the exam papers of the targeted forty students. Once photocopied, the first page, which contained students' identities, was removed from each exam copy. Then, all copies were numbered from 1 to 40. Later, a pair of literature teachers rated the first semester poetry samples and another pair the second semester fiction samples. Similarly, a pair of cultural studies teachers scored the first semester exam samples on British history and another pair marked the second semester exam samples on US history. All these teachers were lecturers who taught the courses and participated in the preparation and administration of the exams during the academic year. They kindly volunteered to re-rate the writing samples using the modified scoring rubric. The researcher took the necessary time to clarify the scale to them.

\subsection{Data analysis}

The hypothesis testing technique using the T-Test Paired two Sample for Mean was used in order to analyze the transfer of the skills learned in the ESAP writing course to other courses. Two hypotheses are used. The first one is the Null Hypothesis $\mathrm{H}_{0}$ that assumes that there is no statistically significant difference between the means of two samples. The second one is the Alternative Hypothesis $\mathrm{H}_{\mathrm{a}}$ that assumes that there is a significant difference in the means. A two-tailed test was used because although there was expectation that the data analysis would show positive transfer of learning, the opposite can happen.

With a two-tailed hypothesis testing, the null hypothesis is rejected if the t-test statistic, computed from the data, falls in either side of the critical region. In other words, testing the possibility of a relationship is done in both directions. Finally, in order to measure the impact of the ESAP writing on students' writing performance and on learning transfer, the average of the scores of 
each pair of raters was used. This average was used to test whether there was a statistically significant difference in the means of the raters' average scores in the pre-test and in each exam in semester 1 and 2. The following two hypotheses were tested:

Null Hypothesis $\mathrm{H}_{0}=$

Alternative Hypothesis $\mathrm{H}_{\mathrm{a}}=$
There is no difference in the means of the pair of raters' averages for the pretest and the raters' averages for the exam; thus, there is no transfer.

There is a difference in the means of the raters' scores; thus, there is transfer.

\section{Results and Discussion}

In order to understand the role ESAP writing instruction plays in promoting transfer of learning, the course should help students demonstrate learning at the end of instruction, and "any kind of demonstration of learning, by definition, involves transfer" (James, 2014, p. 4). Therefore, the progress that students made at the end of instruction was taken as evidence for learning transfer in this study. Table 4.1 provides a description of the progress that students made in the ESAP writing course, the initial learning text, as well as in the other courses over the two semesters of ESAP writing instruction. As can be seen, students' progress was mostly noticeable in semester 2 of the ESAP writing course. Students made significant improvement in terms of overall writing quality (2.96). Apparently, content (1.13) played an important role in this improvement, which was quite expected given the central role content played during instruction. Unlike other writing pedagogies such as process writing and the product approach which relegate content to a secondary status (Horowitz, 1986), the ESAP writing course in this study placed a great emphasis on content by creating a strong link between reading and writing. This emphasis appeared to have helped students focus their attention on meaning. Indeed, integrating reading and writing seemed to have helped students gain a better understanding of the readingwriting relations in academic studies (Grabe, 2003). Students' positive results in content may also indicate that the equal focus that was placed on reading and writing helped students develop a sense of audience. In other words, the gradual mastery of textresponsible writing (Leki \& Carson, 1997) that students could demonstrate from semester 1 to semester 2 reflected in some ways their understanding of the requirements of the academic community.

In general, the findings indicated that the ESAP writing course had a positive impact on the development of the students' academic writing skills and consequently on learning transfer. As argued by some researchers, one important principle that can promote transfer is the degree of mastery of initial learning (Bransford et al., 2000; Bransford \& Schwartz, 1999). Following this, the improvement that students demonstrated in the ESAP writing course at the end of instruction seemed quite adequate to provide a basis for learning to transfer to other courses. The findings yielded information on both near transfer and far transfer.

Table 4.1 Transfer ranking

\begin{tabular}{|l|l|l|l|l|l|l|l|l|}
\hline Exam & Content & Org. & Vocab. & $\begin{array}{l}\text { Lang. } \\
\text { Use }\end{array}$ & Mc. & T/S & Trans. Av. & Rank \\
\hline S1_ESAP & 0.58125 & 0.618 & 0.306 & 0.168 & 0.071 & 1.740 & 0.581 & $4^{\text {th }}$ \\
\hline S2_ESAP & 1.1375 & 0.868 & 0.481 & 0.537 & 0.068 & 2.968 & 1.010 & $1^{\text {st }}$ \\
\hline S1_TFEL & 0.00625 & 0.725 & 1.056 & -1.618 & -0.012 & 0.137 & 0.048 & $6^{\text {th }}$ \\
\hline S2_TFEL & 0.91875 & 1.287 & 1.725 & -1.075 & 0.037 & 2.787 & 0.946 & $2^{\text {nd }}$ \\
\hline S1_Poetry & 0.33125 & 0.331 & -0.025 & -2.356 & -0.093 & -2.556 & -0.728 & $8^{\text {th }}$ \\
\hline S2_Fiction & 0.35 & 1.062 & 0.412 & -1.656 & -0.025 & 0.137 & 0.046 & 7 th \\
\hline S1_British history & 0.63125 & 1.237 & 1.237 & -1.287 & 0.112 & 0.65 & 0.430 & $5^{\text {th }}$ \\
\hline S2_US history & 1.06875 & 1.175 & 1.175 & -1.875 & 0.001 & 2 & 0.590 & $3^{\text {rd }}$ \\
\hline Total transfer & 4.3625 & 7.306 & 6.368 & -9.162 & 0.160 & 7.865 & & \\
\hline Transfer average & 0.4406 & 0.969 & 0.930 & -1.644 & 0.003 & 0.526 & & \\
\hline Percent transfer & $38.74 \%$ & $111.63 \%$ & $193.29 \%$ & $-306.01 \%$ & $4.85 \%$ & $17.72 \%$ & & \\
\hline Rank & 3 rd & 2 nd & 1 st & 6 th & 5 th & 4 th & & \\
\hline
\end{tabular}

Percent transfer $=($ Mean_2minusMean_1) divide by [(Mean_1 + Mean_2) $/ 2]$

Mean_1 = Mean of scores for pre-test; Mean_2 = Mean of scores for Exam

James's (2014) review of research on learning transfer in EAP contexts included only the experimental studies that investigated the effect of EAP instruction on learning transfer within the same course. That is, learning transfer was observed in relation to the learning that the case study subjects could demonstrate after a certain period of instruction. From this perspective, learning transfer is assumed in students' performance (James, 2008; James, 2014). The type of transfer that James (2014) identified in these studies 
was mostly near transfer. The ESAP writing course in the present study also served as a transfer context in the sense that students were expected to demonstrate learning at the end of instruction. Therefore, similar to James's (2014) findings, the results from the analysis of the students' writing samples showed that the kind of transfer that occurred most was near transfer since improvement in the students' writing quality was mostly observed in the writing course.

The findings also revealed that near transfer occurred quite frequently in the TEFL course. The ESAP course and TEFL were strongly linked in terms of reading content, activities, skills, strategies, and writing genres. In addition, the hugging strategies (Perkins \& Salomon, 1988; Fogarty et al., 1992) were carefully applied during instruction in both subjects. Results from the descriptive analysis showed that learning transfer in the TEFL course varied significantly from one semester to another. Indeed, very poor transfer was observed in the first semester. The transfer average was almost nil with just 0.04 . Nevertheless, students made a significant improvement in S2 TEFL. This improvement was basically seen in the total score (2.78) vocabulary (1.72), organization (1.28), and content (0.91). Interestingly, the vocabulary component was the best performer in terms of transfer. Indeed, students seemed to have made considerable improvement in vocabulary in both semesters. These positive results may be attributable to the ESAP course which offered students constant exposure to the TEFL content as well as opportunities to use specialized vocabulary in oral presentations, summaries, and essay writing. This lends support to Storch and Tapper's (2009) findings that showed that academic vocabulary development can be enhanced by encouraging students to notice appropriate vocabulary when, for example, referring to authors' works and when providing feedback on students' writing.

In addition, time appeared to be an important factor that influenced learning transfer. The fact that learning transfer was much more frequent in the second semester indicated that students needed more time to get used to the type of EAP writing instruction and to the TEFL content both of which they had been introduced to for the first time. These findings support the view that learning transfer is a long process and needs time to occur (Haskell, 2001). They also support Perkins and Salomon's (1988) view that learning transfer is not an automatic process. In addition, Salomon and Perkins (1989) argue that low road transfer (near transfer) requires a certain degree of mastery of initial learning and that 50 hours of practice or even a two-year course may not be sufficient to attain the required level of "near-automaticity" (p.129). The findings of this study revealed that the first semester of ESAP writing instruction was insufficient for near transfer to occur frequently. Although students seemed to have made rather significant improvement in the second semester compared to the first semester, they still had to go a long way in order to reach the required level of learning.

As can be seen in Table 4.1, far transfer was rare in literature. Students made no significant improvement in both semesters with an average transfer of -0.72 in S1 and 0.046 in S2. A marginal improvement was observed in terms of content (0.33) in both S1 and S2. The only noticeable improvement was at the level of organization with 1.06 in S2. However, far transfer occurred more frequently in cultural studies. Results showed that students made significant improvement in terms of content (1.06) in S2. Students' progress was also observable at the level of organization. Interestingly, students' performance in this component was still slightly better in S1 with 1.23 than in S2 with 1.17. The same percent progress was observed at the level of vocabulary in S1 and S2. In general, it can be said that far transfer occurred, though in a very constrained way. However, these results should be taken with caution because despite more than a hundred years of learning transfer research, far transfer is still an elusive phenomenon (James, 2014).

The findings suggest that an ESAP writing course that is focused on teaching for transfer can promote learning transfer. Perkins and Salomon's (1988) hugging strategies, which were blended into writing instruction, appeared to have played an important role in encouraging near transfer. Green (2015) noted that providing hugging and bridging strategies should not be the responsibility of the EAP instructor alone. He argued that disciplinary instructors also play a crucial role in encouraging learning transfer by making their expectations as clear as possible and by collaborating with the EAP instructors. In the present study, the researcher acted as the EAP and the disciplinary instructor who had a very clear idea of the objectives of both the EAP writing course and the TEFL course. Moreover, the fact that these two courses were linked and taught by the same instructor seemed to have played a crucial role in helping students better understand the relevance of the writing skills and strategies they were learning in the writing course to their TEFL course. This approach allowed for a more effective use of the hugging strategies during instruction, which in turn led to transfer of learning.

On the other hand, it appeared that the bridging strategies did not have a big impact on far transfer. This can be explained by the fact that the other disciplinary instructors - literature and cultural studies lecturers - did not play an active role in encouraging learning transfer. No collaboration at all occurred between the EAP instructor and these lecturers. Far transfer could have occurred more frequently if the disciplinary lecturers had played a more active role in promoting learning transfer to their respective courses. As suggested by Green (2015), this could be done by making the hugging-bridging techniques explicit to them, inviting them to make their expectations clearer, and apprising them of the contents and intended outcomes of the EAP courses. 


\section{Conclusion}

The present research sought to investigate the impact of a teaching-for-transfer ESAP writing course on learning transfer to subject-specific courses. Perkins and Salomon's (1988) hugging-bridging techniques were blended into instruction to promote learning transfer. The findings suggested that the type of transfer that occurred most was near transfer. It occurred in the TEFL course almost as frequently as in the ESAP writing course. The improvement that students made in these courses related particularly to content, organization, and vocabulary. The hugging techniques which allowed to link these courses in terms of content, skills, activities, strategies, and writing genres, seemed to have played an important role in encouraging near transfer. Another important factor that helped promote this type of transfer was the fact that both courses were taught by the same instructor. Far transfer, on the other hand, occurred in a very constrained way.

The findings have important implications for writing instruction in EAP contexts. They demonstrated that Perkins' and Salomon's (1988) hugging-bridging techniques blended within an ESAP course increase the chances for learning transfer to occur. While far transfer is quite difficult to achieve, instructors can at least work to promote near transfer. Nevertheless, the bridging techniques can be used to encourage far transfer, and their effectiveness can be enhanced by making them more explicit to both students and disciplinary lecturers. In fact, the success of such courses depends largely on the level of collaboration that the disciplinary lecturers are willing to provide. That is, promoting learning transfer is a shared responsibility between the EAP instructors and the disciplinary lecturers.

Finally, the present study had some limitations that should be addressed in future research. First, because learning transfer was assumed in the improvement the students could demonstrate at the end of instruction, the findings gave only a general picture of learning transfer. They did not reveal what learning outcomes transferred and to where. It would be useful to conduct other studies that will demonstrate what learning outcomes can transfer from the initial learning context to other contexts. Second, this study involved a rather small number of students. Other studies which include larger samples are needed. Finally, investigating learning transfer over a period of just one year is not enough. Transfer of learning is a long process and takes time to develop. Thus, other longitudinal studies that are carried over longer periods can give a clearer picture of learning transfer.

Funding: This research received no external funding.

Conflicts of Interest: The author declares no conflict of interest.

\section{References}

[1] Anderson, N.J. (2002). The role of metacognition in second language teaching and learning. ERIC Digest. Retrieved from http://eric.ed.gov/?id=ED463659

[2] Baik, C., \& Greig, J. (2009). Improving the academic outcomes of undergraduate ESL students: The case for discipline-based academic skills programs. Higher Education Research \& Development, 28 (4), 401-416. http://doi.org/10.1080/07294360903067005

[3] Barnett, S. M., \& Ceci, S. J. (2002). When and where do we apply what we learn? A taxonomy for far transfer. Psychological Bulletin, 128, 612-637.

[4] Bransford, J. D., \& Schwartz, D. (1999). Rethinking transfer: A simple proposal with multiple implications. Review of Research in Education, 24, 61-100. doi.org/10.3102/0091732X024001061.

[5] Bransford, J.D., Brown, A., \& Cocking, R. (2000). How people learn: Brain, mind, experience, and school. Expanded edition. National Academics Press. Retrieved from: http://www.digitalbookocean.info/etext/12754how people learn brain mind experience and school expanded edition.pdf

[6] Butterfield, E. C., \& Nelson, G. D. (1989). Theory and practice of teaching for transfer. Educational Technology Research and Development, 37,3, 5-38. doi.org/10.1007/BF02299054.

[7] Cheng, A. (2007). Transferring generic features and recontextualizing genre awareness: Understanding writing performance in the ESP genre-based literacy framework. English for Specific Purposes, 26, 287-307.

[8] Counsell, J. (2011). How effectively and consistently do international postgraduate students apply the writing strategies they have been taught in a generic skills-based course to their subsequent discipline-based studies? Journal of Academic Language and Learning, 5, A1A17.

[9] Crusan, D. (2010). Assessment in the second language writing classroom. The University ofMichigan Press.

[10] Dornyei, Z. (2007). Research methods in applied linguistics. Oxford University Press.

[11] Fogarty, R., Perkins, D., \& Barell, J. (1992). How to teach for transfer. Skylight Publishing.

[12] Gick, M. L., \& Holyoak, K. J. (1983). Schema induction and analogical transfer. Cognitive Psychology, 15, 1-38. doi:10.1016/00100285(83)90002-6.

[13] Grabe, W. (2003). Reading and writing relations: Second language perspectives on research and practice. In B. Kroll (Ed.), Exploring the dynamics of second language writing, pp. 242-262. Cambridge University Press.

[14] Green, J.H., (2015). Teaching for Transfer in EAP: Hugging and bridging revisited. English for Specific Purposes 37, 1-12, http://dx.doi.org/10.1016/j.esp.2014.06.003

[15] Halpern, D. F., \& Hakel, M. D. (2003). Applying the science of learning to the university and beyond: Teaching for long-term retention and transfer. Change, July/August, 2-13 doi.org/10.1080/00091380309604109 
[16] Haskell, R. E. (2001). Transfer of learning: Cognition, instruction, and reasoning. Academic Press.

[17] Hill, C., Khoo, S., \& Hsieh, Y. (2020). An investigation into the learning transfer of English for Specific Academic Purposes (ESAP) writing skills of students in Singapore. Journal of English for Academic Purposes 48, doi.org/10.1016/j.jeap.2020.100908

[18] Horowitz, D. M. (1986). Essay examination prompts and the teaching of academic writing. English for Specific Purposes. Vol. 5. No. 2. pp. 107 $-120$.

[19] Jacobs, H., Zinkgraf, S., Wormuth, D., Hartfield, V. \& Hughey, J. (1981). Testing ESL composition: A practical approach. Newbury House.

[20] James, M. A. (2006). Teaching for transfer in ELT. ELT Journal, 60, 2, 151-159. doi.org/10.1093/elt/cci102

[21] James, M. A. (2008). The influence of perceptions of task similarity/difference on learning transfer in second language writing. Written Communication, 25, 76-103.

[22] James, M. A. (2009). "Far" transfer of learning outcomes from an ESL writing course: Can the gap be bridged? Journal of Second Language Writing, 18, 2, 69-84.

[23] James, M. A. (2010a). Transfer climate and EAP education: Students' perceptions of challenges to learning transfer. English for Specific Purposes, 29, 133-147. doi:10.1016/j.esp.2009.09.002

[24] James, M. A. (2010b). An investigation of learning transfer in English-for-general-academic- purposes writing instruction. Journal of Second Language Writing, 19, 183-206.

[25] James, M.A. (2012). An investigation of motivation to transfer second language learning. The Modern Language Journal, 96, 1. doi: 10.1111/j.1540-4781.2012.01281.

[26] James, M.A (2014). Learning transfer in English-for-academic-purposes contexts: A systematic review of research. Journal of English for Academic Purposes 14, 1-13. doi.org/10.1016/j.jeap.2013.10.007

[27] Johns, A. M. (1993). Reading and writing tasks in English for academic purposes classes: Products, processes, and resources. In J. G. Carson \& I. Leki (Eds.), Reading in the composition classroom, pp. 274-289. Heinle and Heinle.

[28] Leki, l., \& Carson, J. G. (1997). Completely different worlds: EAP and the writing experiences of ESL students in university courses. TESOL Quarterly, 31, 39-69.

[29] Mackey, A. \& Gass, S.M. (2005). Second language research: Methodology and design. Lawrence Erlbaum Associates.

[30] Marini, A., \& Genereux, R. (1995). The challenge of teaching for transfer. In A. McKeough, J. Lupart, \& A. Marini (Eds.), Teaching for transfer: Fostering generalization in learning, pp. 1-20. Lawrence Erlbaum.

[31] Perkins, D. N., \& Salomon, G. (1988). Teaching for transfer. Educational Leadership, 46, 1, 22-32. Retrieved from http://www.ascd.org/ASCD/pdf/journals/ed lead/el 198809 perkins.pdf.

[32] Perkins, D. N., \& Salomon, G. (1992). Transfer of learning. Contribution to The International Encyclopedia of Education, Second Edition. Pergamon. Retrieved from http://jaymctighe.com/wordpress/wp-content/uploads/2011/04/Transfer-of-Learning-Perkins-and-Salomon.pdf

[33] Richards, J.C. \& Rodgers, T.S. (2014). Approaches and methods in language teaching (3 ${ }^{\text {rd }}$ ed.). Cambridge University Press.

[34] Rose, D. \& Martin, J.R. (2012). Learning to write, reading to learn: genre, knowledge and pedagogy in the Sydney school. Equinox.

[35] Salomon, G., \& Perkins, D. N. (1989). Rocky roads to transfer: Rethinking mechanisms of a neglected phenomenon. Educational Psychologist, 24, 2, 113-142 http://dx.doi.org/10.1207/s15326985ep2402 1

[36] Shrestha, P.N. (2017). Investigating the learning transfer of genre features and conceptual knowledge from an academic literacy course to business studies: Exploring the potential of dynamic assessment. Journal of English for Academic Purposes, 25, 1-17. doi.org/10.1016/j.jeap.2016.10.002.

[37] Storch, N. \& Tapper, J. (2009). The impact of an EAP course on postgraduate writing. Journal of English for Academic Purposes, 8, $207-223$.

[38] Terraschke, A., \& Wahid, R. (2011). The impact of EAP study on the academic experiences of international postgraduate students in Australia. Journal of English for Academic Purposes, 10, 173-182.

[39] Thorndike, E. L., \& Woodworth, R. S. (1901). The influence of movement in one mental function upon the efficiency of other functions. Psychological Review, 8, 247-261.

[40] Weigle, S.C. (2002). Assessing writing. Cambridge University Press.

[41] Wingate, U. (2016). Academic literacy across the curriculum: Towards a collaborative instructional approach. Language Teaching, 1-16. doi:10.1017/S0261444816000264.

[42] Zarei, G. R., \& Rahimi, A. (2014). Learning transfer in English for general academic purposes writing. SAGE Open, 4 (1). https://doi.org/10.1177/ 2158244013518925, 2158244013518925. 